Vol 12, Issue 10, 2019

\title{
FORMULATION AND EVALUATION OF FAST DISSOLVING SUBLINGUAL FILM OF PAROXETINE HYDROCHLORIDE FOR TREATMENT OF DEPRESSION
}

\author{
RITA N WADETWAR*, FARHEEN ALI, PRANITA KANOJIYA
}

Department of Pharmaceutical Sciences, Rashtrasant Tukadoji Maharaj Nagpur University, Nagpur, Maharashtra, India. Email: rnwadetwar@gmail.com

Received: 25 June 2019, Revised and Accepted: 06 August 2019

\section{ABSTRACT}

Objective: Oromucosal route could be an alternative over the conventional route for paroxetine hydrochloride (PXH) as it offers direct systemic delivery, by avoiding extensive first-pass metabolism, which results in poor systemic absorption. The film dissolves quickly when placed in mouth without need of water thus helpful in providing rapid onset of action.

Methods: Fast dissolving film of PXH was prepared using Pullulan in various combinations of $3^{2}$ full factorial design by solvent casting technique. Prepared films were subjected to mechanical, in vitro, and ex vivo characterization.

Results: The physicochemical characteristics such as mass uniformity, thickness, surface pH, and folding endurance were found satisfactory. The formulation (F3) containing $4 \% \mathrm{w} / \mathrm{v}$ Pullulan showed maximum release $94.31 \%$ and ex vivo permeation $92.67 \%$ through goat oral mucosa in 15 min. Uniform drug loading was observed in all the batches with disintegration time $<25$ s. Fourier transform infrared spectroscopy study revealed the compatibility of drug with polymer. Scanning electron microscopy revealed that there was uniform mixing of all ingredients. Optimized batch F3 was found to be stable for 1 month as no significant changes were observed in \% cumulative drug release and weight of film.

Conclusion: Pullulan a natural biodegradable polymer allocates good physical property to film. Hydrophilic nature of polymer imparts fast disintegrating property to film.

Keywords: Fast dissolving film, Paroxetine hydrochloride, Pullulan, Solvent casting.

(C) 2019 The Authors. Published by Innovare Academic Sciences Pvt Ltd. This is an open access article under the CC BY license (http://creativecommons. org/licenses/by/4. 0/) DOI: http://dx.doi.org/10.22159/ajpcr.2019.v12i10.34690

\section{INTRODUCTION}

Research work on oral drug delivery has led to the progress of solid oral dosage forms in the form of fast dissolving films (FDF). FDF can be defined as a dosage form that employs a water-soluble polymer (generally a hydrocolloid, which may be a bioadhesive polymer), which allows the dosage form to quickly wet, adhere, and dissolve to release the drug when placed on the tongue or in the oral cavity for oromucosal absorption [1]. The geriatric, paediatric, mentally ill and non-cooperative patients often find difficulty in swallowing tablets and capsules. Also when patients travel, there are circumstances when water is not available with them, during such conditions FDF is one of the good approach for curbing such problems.

It is the most preferred formulation due to ease of administration, preparation, handling, transportation, palatability, and dose uniformity. FDF is highly accepted for oral delivery of various potent drugs (e.g., analgesics, anti-histamines, anti-asthmatics, cardiovascular drugs, and neuroleptics) in contrast to immediate release orodispersible tablets (ODT). Although ODT was designed for fast disintegration in mouth, their risk of choking and non-compliance for certain patients can still exist, while FDF formulation can resolve the problem of swallowing thus improves patient compliance. FDF has the benefit of large surface area for rapid dissolution and hence consumer-friendly. Various hydrophilic polymers are used as film formers for FDF such as Pullulan, hydroxypropyl methylcellulose (HPMC), polyvinyl alcohol, maltodextrin, and Kollicoat ${ }^{\circledR}$ IR [2].

Pullulan is a natural biodegradable-biocompatible, non-ionic watersoluble extracellular film-forming polysaccharide, obtained from the fermentation medium of the black yeast such as Aureobasidium Pullulan. Pullulan based films show low oxygen permeability, are oil and grease resistant, being a natural one are superior over synthetic polymers. Pullulan films are non-toxic, non-immunogenic, non-mutagenic, nonreducing, hydrophilic, tasteless, colorless, resistant to oil, heat-stable, and impermeable to oxygen [2]. Based on these properties and advantages of Pullulan, it was used as a film former in present investigation.

After sublingual administration, the drug substances are rapidly absorbed into the reticulated vein underneath the oral mucosa, and transported through the facial veins, internal jugular veins, and brachiocephalic vein and then drained into systemic circulation thereby avoiding the hepatic first-pass effect [3]. In terms of the permeability sublingual area of the oral cavity is more permeable than other mucosal area. Sublingual films have been developed for certain condition, for example, migraines, bipolar mania, and other mental illness for which rapid onset of action is desired.

According to the World Health Organization, major depression has become the second most prevalent cause of illness-induced disability worldwide [4]. Paroxetine hydrochloride ( $\mathrm{PXH})$ is a potent and selective inhibitor of (5-HT, serotonin) 5-hydroxytryptamine uptake used in the treatment of obsessive-compulsive disorder, panic disorder, and social anxiety disorder/social phobia. PXH is well absorbed after oral dosing and undergoes extensive first-pass metabolism thus results in poor oral bioavailability $31 \pm 15 \%$ [5]. It is available as conventional oral film-coated tablets (20 mg), mouth dissolving tablets $(10 \mathrm{mg})$ in the market. This justifies the need for the development of other effective alternative such as FDF formulation as the mouth dissolving tablet has its own limitations.

Hence, based on the justification and background of Pullulan and $\mathrm{PXH}$, the aim of the present investigation was to formulate and 
evaluate palatable Pullulan based FDF of PXH following optimization of process factors. The proposed formulation has potential to improve compliance and quick onset of action in depressed patients than the available tablets of PXH. This PXH loaded Pullulan based FDF presents numerous advantages over its marketed oral dosage forms such as ease of administration without water, easy to formulate, simplicity to handle, and carry away.

\section{MATERIALS AND METHODS}

\section{Materials}

PXH was obtained as a gift sample from Sun Pharmaceutical Industries Ltd., Mumbai. Pullulan was obtained from Gangwal chemicals, Mumbai. Polyethylene glycol (PEG) 600, citric acid, and sucralose were procured from Loba Chemie Ltd., Mumbai, India. All other reagents used were of analytical grade. Purified water was used for study.

\section{Preformulation studies}

Preformulation may be described as a phase of the research and development process where the formulation scientist characterizes the physical, chemical, and mechanical properties of new drug substances, to develop stable, safe, and effective dosage forms. During this evaluation, possible interaction with various inert ingredients intended for use in final dosage form is also considered [6].

\section{Calibration curve of PXH in phosphate buffer (pH 6.8)}

A stock solution of PXH of concentration $100 \mu \mathrm{g} / \mathrm{ml}$ was prepared in phosphate buffer ( $\mathrm{pH}$ 6.8). The above stock solution was further diluted to get concentration in the range of $10-80 \mu \mathrm{g} / \mathrm{ml}$, and standard calibration curve was plotted. The absorbance of the prepared solutions was observed at $\lambda \quad 293 \mathrm{~nm}$ using UV-visible spectrophotometer (Jasco UV Model V-630) [5,6]. The calibration curve was used for the estimation of drug content in formulation and for ex vivo diffusion studies [6].

\section{Drug excipient compatibility study}

Excipients are important components of almost all pharmaceutical dosage forms. The successful formulation of a stable dosage form depends on the careful selection of the excipients, which are added to facilitate administration, to promote the consistent release and bioavailability of the drug, and protect it from degradation. PXH along with excipients in 1:1 ratio was kept in the stability chamber at $40^{\circ} \mathrm{C} \pm 2^{\circ} \mathrm{C}$ temperature and $75 \pm 5 \%$ relative humidity (RH) for 1 month. The samples were withdrawn at the end of a month and evaluated for compatibility studies by differential scanning calorimetry (DSC) and Fourier transform infrared spectroscopy (FTIR).

\section{Drug-excipient compatibility study by FTIR}

FTIR study was performed by $\mathrm{KBr}$ powder mixing method using FTIR spectrophotometer (Shimadzu Corporation, Japan, 8101A) and the spectrums were recorded in the wavelength region of $4000-400 \mathrm{~cm}^{-1}$.

\section{Drug-excipient compatibility study by DSC}

DSC analysis of PXH and its physical mixture (PM) with polymer was performed using Shimadzu DSC 60 Plus and thermal data obtained were processed using TA60 software System. Thermal behavior was studied by heating $2 \mathrm{mg}$ of sample in crimped aluminum pans at a scanning rate of $5^{\circ} \mathrm{C} / \mathrm{min}$ in the atmosphere of nitrogen gas flow $100 \mathrm{ml} / \mathrm{min}$ over the temperature range of $30-300^{\circ} \mathrm{C}[5,6]$.

\section{Formulation design of oral FDFs}

Preliminary trial

Different plasticizers such as PEG 400, glycerol, and PEG 600 were screened with Pullulan film by considering three parameters, i.e., disintegration time (DT), folding endurance, and appearance [6].

\section{Experimental design}

The objective of the present investigation was to observe the combined effect of the concentration of polymer as well as the concentration of plasticizer on the DT, in vitro \% drug release and folding endurance for obtaining the optimized FDF. The experimental design was generated by Design-Expert ${ }^{\circledR}$ software (Version 11, Stat-Ease Inc., USA). In this work, a $3^{2}$ factorial design was used for the optimization of FDF. A 2 -factor was evaluated each at three levels, and experimental trials were performed on all nine combinations. A statistical model incorporating interactive and polynomial terms were used to evaluate the response using the equation:

$$
\mathrm{Y}=\mathrm{b}_{0}+\mathrm{b}_{1} \mathrm{X}_{1}+\mathrm{b}_{2} \mathrm{X}_{2}+\mathrm{b}_{12} \mathrm{X}_{1} \mathrm{X}_{2}+\mathrm{b}_{11} \mathrm{X}_{12}+\mathrm{b}_{22} \mathrm{X}_{22}
$$

Where $\mathrm{Y}$ is the dependent variable, $\mathrm{b}_{0}$ is the arithmetic mean response of the nine runs, and $b_{1}$ is the estimated coefficient for the factor $X_{1}$. The main effects $\left(X_{1}\right.$ and $\left.X_{2}\right)$ represent the average result of changing one factor at a time from its low to high value. The interaction terms $\left(\mathrm{X}_{1}\right.$ and $\left.\mathrm{X}_{2}\right)$ show how the response changes when two factors are simultaneously changed. The polynomial terms $\left(\mathrm{X}_{12}\right.$ and $\left.\mathrm{X}_{22}\right)$ are included to investigate nonlinearity. The above equation indicates a coefficient with the negative sign which shows that there is an increase in response when factor level is decreased from higher to lower level, and the factor with higher absolute value of coefficient and lower value " $p$ " has major effect on the response variables. A $3^{2}$ randomized full factorial design was utilized to study systematically the effects of two independent factors on the characteristics of the film [6].

\section{Preparation of PXH loaded Pullulan based FDF}

FDF of PXH was prepared using Pullulan in various combinations as per $3^{2}$ full factorial design by solvent casting technique. Required quantity of citric acid (saliva stimulator) was added in aqueous Pullulan solution to minimize recrystallization of PXH. It was allowed to stir for few minutes using magnetic stirrer (Labman Scientific Instruments, India) until it dissolved. On its dissolution, $175 \mathrm{mg}$ of accurately weighed PXH (Electronic balance, AUX 120, Shimadzu, Japan) was added with stirring. When the solution was clear, smooth and homogeneous, accurately weighed $300 \mathrm{mg}$ of PEG 600, needful quantities of sucralose and mint flavor $(5 \mathrm{mg}$ ) were added to the preparation with stirring to get clear homogeneous preparation. The solution was allowed to stand for $1 / 2 \mathrm{~h}$ to remove air-bubble if any. The formulation was casted on a suitable platform using a film-forming machine (VJ Instruments, Lat., India) and dried at $45-50^{\circ} \mathrm{C}$ to form a film. The film was then carefully removed and cut into suitable size, i.e., $2 \mathrm{~cm} \times 2 \mathrm{~cm}$ and stored in aluminum sachets at $2-8^{\circ} \mathrm{C}$ until further studies. The composition of FDF is shown in Table 1.

Table 1: Composition of FDF

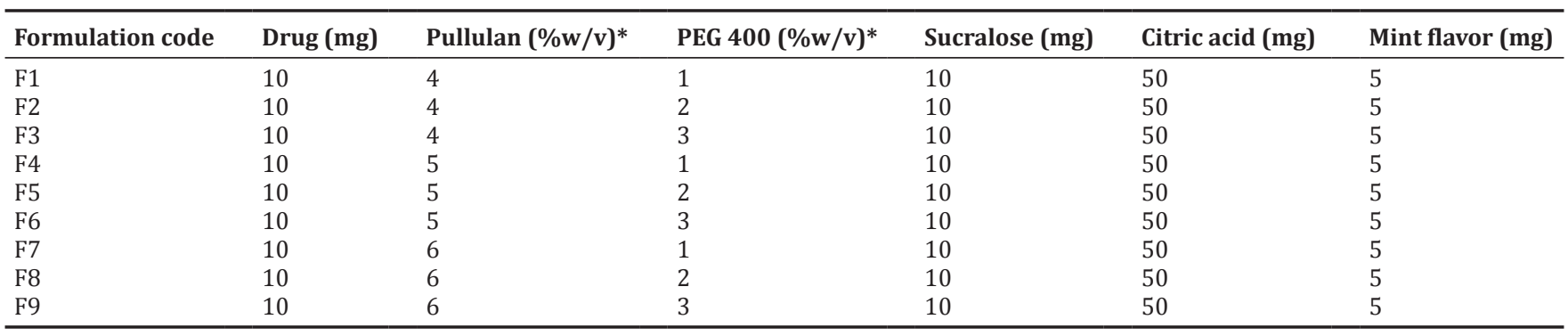

*All the ingredients were added in weight (g)/volume (ml). Total volume of the polymer solution including drug and plasticizer was 6 ml. FDF: Fast dissolving films 
Dose calculation

The dose of PXH is $10 \mathrm{mg}$. Therefore, amount of PXH required in $4 \mathrm{~cm}^{2}$ of the film is $10 \mathrm{mg}$.

$$
\begin{aligned}
& \text { Area of film }=7 \times 10=70.00 \mathrm{~cm}^{2} \\
& \text { Area of film }=2 \times 2 \mathrm{~cm}=4 \mathrm{~cm}^{2} \\
& \quad 4 \mathrm{~cm}^{2} \text { contains } 10 \mathrm{mg}
\end{aligned}
$$

(70.00) $\mathrm{cm}^{2}$ contains $=175 \mathrm{mg}$ of PXH $[6,7]$.

\section{Characterization of FDF}

This parameter was checked simply by visual inspection of films and evaluation of texture by feel or touch. FDFs of PXH were evaluated for their weight, thickness, $\mathrm{pH}$ value, folding endurance, drug content, DT, and in vitro dissolution. All studies were carried out on films of $2 \times 2 \mathrm{~cm}^{2}$ area in triplicate, and average values were reported [8].

\section{Physical and mechanical properties}

Uniformity of weight and thickness of the films were estimated using digital weighing balance and Vernier caliper (MGW Precision tools, India), respectively. Folding endurance was ascertained by repeatedly folding one film at the same place until it ruptures. The counting of folding made before the film ruptured was denoted as the mean folding endurance. All determinations were performed in triplicate [9].

\section{Surface pH}

Surface $\mathrm{pH}$ was determined using a digital $\mathrm{pH}$ meter (Equiptronics, EQ-611, Mumbai, India) to check whether the film causes irritation to the oral mucosa. Films were placed in closed Petri plate containing $5 \mathrm{ml}$ distilled water. After moistening $\mathrm{pH}$ probe was placed in close contact with the wetted films, and the surface $\mathrm{pH}$ was identified in triplicate. It is necessary that films should have nearly uniform and neutral $\mathrm{pH}$ value [9].

\section{Drug content and \% moisture content}

To evaluate the uniformity of drug content, the films were dissolved in $100 \mathrm{ml}$ phosphate buffer ( $\mathrm{pH}$ 6.8), suitably diluted and analyzed using UV-Visible spectrophotometer at $293 \mathrm{~nm}$. The drug content was determined as mean of three determinations using standard calibration curve. Percentage moisture content was determined in triplicate for each batch since moisture in the film could be crucial as it affects the mechanical strength, adhesive properties, and friability of film [10].

\section{Disintegration time}

For disintegration, the required size of films was placed in the beaker containing $10 \mathrm{ml}$ of $\mathrm{pH} 6.8$ buffer to mimic saliva. The DT was noted for each film at which film started to break apart. All the studies were performed in triplicate for each batch [10].

\section{In vitro \% drug release}

The film samples were subjected to in vitro dissolution studies using USP Type I dissolution apparatus (Electrolab, India) at $37 \pm 0.5^{\circ} \mathrm{C}$ and $50 \mathrm{rpm}$ speed in $300 \mathrm{ml}$ dissolution medium which was phosphate buffer (pH 6.8). Films were submerged into the dissolution media, and appropriate aliquots were withdrawn at 2, 5, 8, 10, and 15 min time intervals. The samples were filtered through Whatman filter paper and analyzed spectrophotometrically at $293 \mathrm{~nm}$ [11].

\section{Ex vivo permeation studies through goat buccal mucosa}

Permeation studies were carried out for optimized batch using the modified Franz diffusion cell of an internal diameter of $2.5 \mathrm{~cm}$. Goat oral mucosa was used as the model membrane. The membrane was stabilized before mounting to remove the soluble components. The mucosa was mounted between the donor and receptor compartments. The receptor compartment was filled with $27 \mathrm{ml}$ of isotonic phosphate buffer of $\mathrm{pH} 6.8$ which was maintained at $37^{\circ} \mathrm{C} \pm 0.2^{\circ} \mathrm{C}$, and the hydrodynamics were maintained by stirring with a magnetic bead at $50 \mathrm{rpm}$. Previously weighed film was placed in intimate contact with the mucosal surface that was previously moistened with a few drops of simulated saliva. The donor compartment was filled with $1 \mathrm{ml}$ of simulated saliva of $\mathrm{pH}$ 6.8. Samples were withdrawn at suitable interval, replacing the same amount with the fresh medium to maintain the sink condition. The percentage of drug permeated was determined spectrophotometrically at $293 \mathrm{~nm}[12,13]$

\section{Scanning electron microscope (SEM)}

For this study, a small section of the optimized film was cut and then mounted onto stubs using double-sided adhesive tape. Then, the section was determined using SEM (ZEISS EVO 18 Germany) [14].

\section{Physical stability}

Stability studies on the optimized formulation were carried out to determine the effect of temperature and humidity on the stability of the drug. The film (optimized batch) was stored in the stability chamber (REMI Elektrotechnik Ltd., Vasai, India) at $40^{\circ} \mathrm{C} \pm 0.5^{\circ} \mathrm{C}$ and $75 \pm 5 \%$ RH for 2 months. The samples were withdrawn after 2 months and subjected for DT, weight of film and in vitro \% drug release studies [14].

\section{RESULTS AND DISCUSSION}

Exploration of the plasticizers for the formulation of oral FDF

Different plasticizer, namely, Glycerol, propylene glycol, and PEG 600 was used for the formulation of FDF. All these films were evaluated for appearance, DT, and folding endurance, as shown in Table 2.

\section{Effect of plasticizer}

All the trial batches were formulated using various types of plasticizer. Plasticizer affects the film separation property of the film. When the concentration of PEG 600 was increased, it also increased the flexibility of the film as compared to the glycerol and propylene glycol films which showed poor flexibility and mechanical strength due to high moisture retaining nature of glycerin, while propylene glycol yields brittle film with moderate flexibility. Furthermore, PEG 600 resulted in better film separation than propylene glycol. The plasticizer affects the flexibility of the films hence folding endurance also got affected. The PEG 600 showed good effect on folding endurance and disintegration time and hence selected as a plasticizer for further batches of the films.

\section{Standard calibration curve of $\mathrm{PXH}$}

The standard calibration curve of PXH was plotted as absorbance versus concentrations. The $\lambda_{\max }$ of PXH in phosphate buffer $\mathrm{pH} 6.8$ was found to be $293 \mathrm{~nm}$. The standard calibration curve of PXH was plotted between 10 and $80 \mu \mathrm{g} / \mathrm{ml}$, as shown in Fig. 1 .

\section{Drug-excipient compatibility by FTIR}

The IR absorbance peak for characteristic functional groups of PXH at $3331.89 \mathrm{~cm}^{-1}$ (N-H stretching), $1521.14 \mathrm{~cm}^{-1}$ (aromatic C-C stretching), $1222.91 \mathrm{~cm}^{-1}$ (C-O stretching), and $2915.16 \mathrm{~cm}^{-1}$ (C-H symmetric

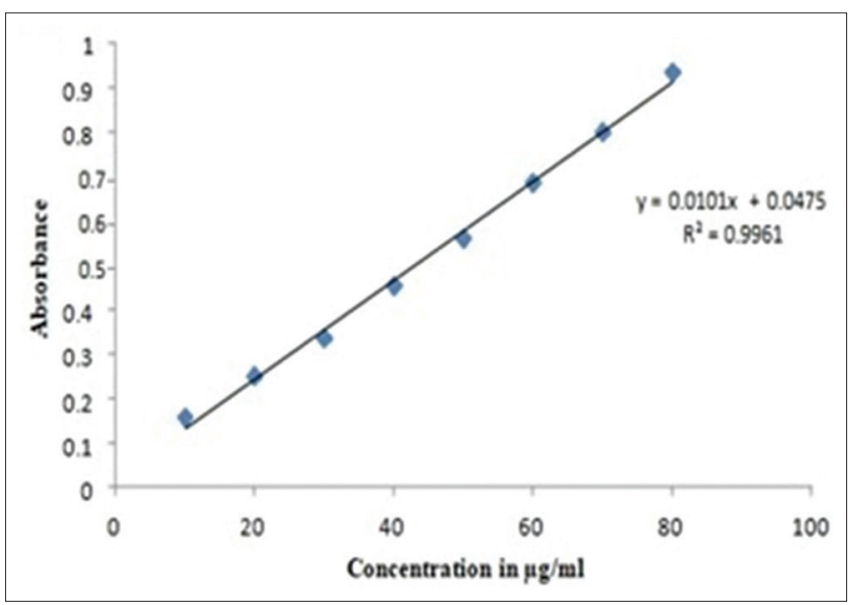

Fig. 1: Calibration curve of paroxetine hydrochloride in phosphate buffer pH 6.8 
stretching) was observed in IR spectra of plain drug. The peaks observed were retained in PM, as shown in Fig. 2a. This indicates that there was no interaction between drug and excipients.

Table 2: Evaluation of trial batches of Pullulan with different plasticizer

\begin{tabular}{lllll}
\hline S. No. & Batch & $\begin{array}{l}\text { Disintegration } \\
\text { time (s) }\end{array}$ & $\begin{array}{l}\text { Folding endurance } \\
\text { (Number of times) }\end{array}$ & $\begin{array}{l}\text { Appearance } \\
\text { of film }\end{array}$ \\
\hline 1. & R1 & 21 & 42 & Transparent \\
2. & R2 & 26 & 33 & Transparent \\
3. & R3 & 15 & 49 & Transparent \\
\hline
\end{tabular}

Drug-excipient compatibility by DSC

PXH showed a sharp endothermic peak at $121.30^{\circ} \mathrm{C}$ corresponding to its melting point. Similarly, the PM of PXH with Pullulan showed a peak at $120.23^{\circ} \mathrm{C}$. There was slight shifting of melting endotherm of PXH in the PM which indicated that there was no interaction between drug and the excipients, as shown in Fig. $2 \mathrm{~b}$.

FTIR and DSC studies suggested that the drug, PXH is compatible with the excipients. From these, it can be concluded that the drug has maintained its identity without losing its characteristic properties. It will not show any adverse effect in action of the formulation and helps to study the desired parameters in the study.

Table 3: Physicochemical characteristics of PXH FDF

\begin{tabular}{|c|c|c|c|c|c|c|c|}
\hline $\begin{array}{l}\text { Batch } \\
\text { code }\end{array}$ & $\begin{array}{l}\text { Disintegration } \\
\text { time (s) }\end{array}$ & $\begin{array}{l}\text { Folding endurance } \\
\text { (Number of times) }\end{array}$ & $\begin{array}{l}\text { In vitro drug } \\
\text { release (\%) }\end{array}$ & Thickness (mm) & $\begin{array}{l}\text { Drug } \\
\text { content (\%) }\end{array}$ & $\begin{array}{l}\% \text { Moisture } \\
\text { content }\end{array}$ & $\begin{array}{l}\text { Weight } \\
\text { variation (mg) }\end{array}$ \\
\hline F1 & $11.31 \pm 1.51$ & $92.23 \pm 1.03$ & $81.55 \pm 0.16$ & $0.03 \pm 0.01$ & $92 \pm 0.48$ & $12.30 \pm 0.07$ & $29.6 \pm 1.52$ \\
\hline $\mathrm{F} 2$ & $12.13 \pm 1.49$ & $98.31 \pm 1.04$ & $88.58 \pm 0.13$ & $0.03 \pm 0.02$ & $95 \pm 0.51$ & $10.44 \pm 0.16$ & $40 \pm 2.00$ \\
\hline F3 & $13.33 \pm 1.52$ & $105.32 \pm 1.06$ & $94.31 \pm 0.15$ & $0.05 \pm 0.01$ & $97 \pm 0.57$ & $10.11 \pm 0.33$ & $40.6 \pm 1.52$ \\
\hline F4 & $15.26 \pm 1.47$ & $91.35 \pm 1.08$ & $78.15 \pm 0.12$ & $0.02 \pm 0.04$ & $88 \pm 0.36$ & $13.01 \pm 0.12$ & $36.3 \pm 1.54$ \\
\hline F5 & $17.34 \pm 1.39$ & $97.34 \pm 1.06$ & $75.48 \pm 0.15$ & $0.04 \pm 0.03$ & $86 \pm 0.53$ & $15.15 \pm 0.27$ & $27.6 \pm 1.51$ \\
\hline F6 & $18.29 \pm 1.44$ & $102.37 \pm 1.02$ & $69.75 \pm 0.14$ & $0.03 \pm 0.02$ & $87 \pm 0.23$ & $14.23 \pm 0.58$ & $34 \pm 2.02$ \\
\hline F8 & $22.32 \pm 1.38$ & $99.36 \pm 1.11$ & $60.70 \pm 0.11$ & $0.03 \pm 0.01$ & $89 \pm 0.46$ & $14.13 \pm 0.40$ & $36 \pm 1.00$ \\
\hline F9 & $24.29 \pm 1.43$ & $104.32 \pm 1.13$ & $62.08 \pm 0.13$ & $0.03 \pm 0.02$ & $87 \pm 0.67$ & $14.92 \pm 0.49$ & $33 \pm 2.04$ \\
\hline
\end{tabular}

Data represent mean \pm standard deviation, $n=3$. PXH: Paroxetine hydrochloride, FDF: Fast dissolving films

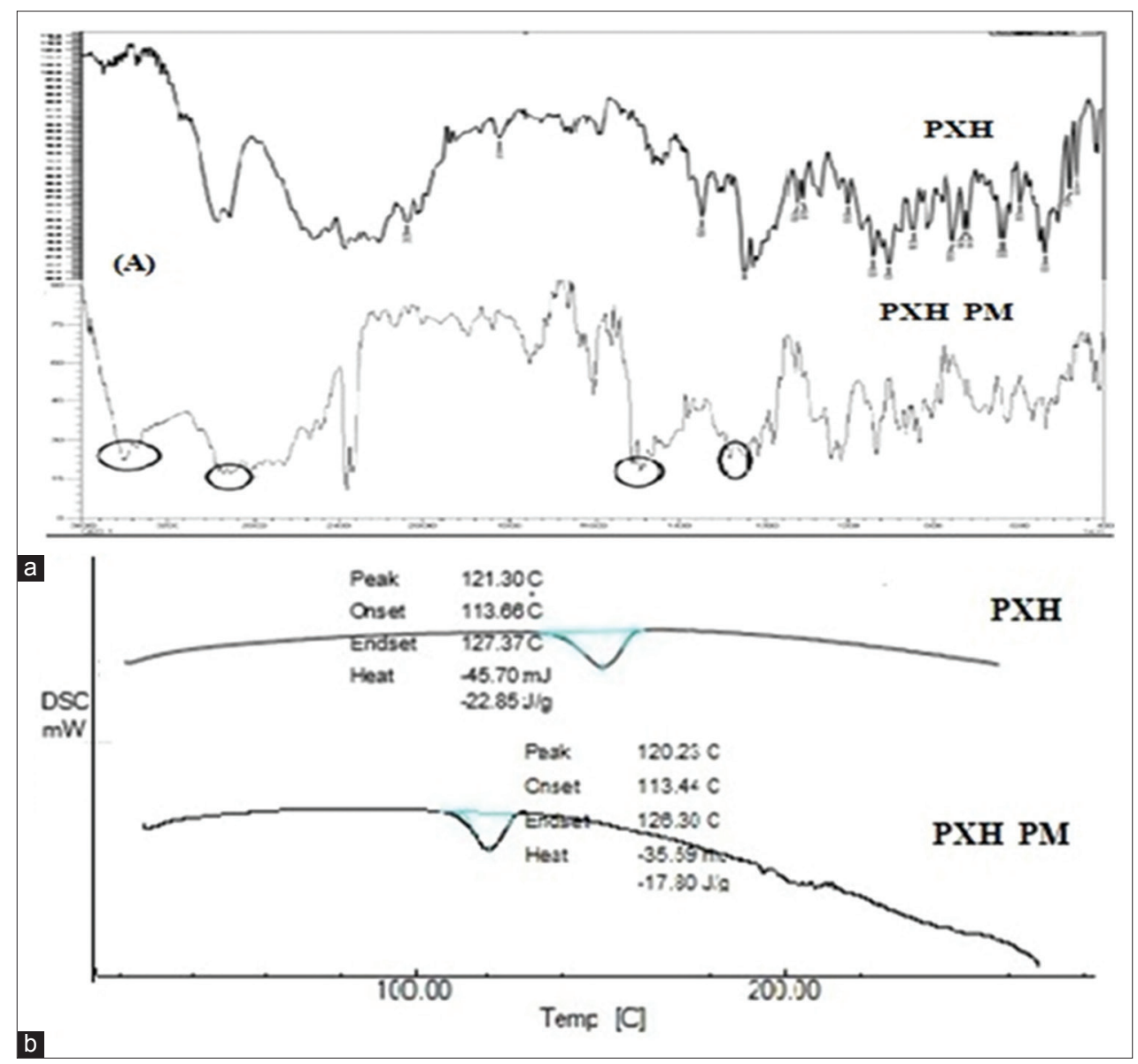

Fig. 2: (a) IR spectra of paroxetine hydrochloride (PXH) and PXH PM (b) differential scanning calorimetry thermogram of PXH and PXH PM 
Physicochemical evaluation of FDF

PXH films were designed with the objective of immediate release of the drug for improved patient compliance and better bioavailability. Therefore, rapidly water-soluble natural polymer such as PullulanÏ was chosen for the formulation. Physicochemical characteristics of the PXH films are shown in Table 3.

\section{Appearance}

The prepared films were found to be smooth, uniform in thickness, mass, drug content without any visible cracks or folds. The physical appearance was checked with a visual inspection of films and texture by feel or touch. Appearances of all the films were transparent, all were having smooth surface and were elegant enough for appearance.

\section{Film thickness}

As all the formulations contain a different concentration of PLN $(4-6 \% \mathrm{w} / \mathrm{v})$ and PEG $600(1-3 \% \mathrm{w} / \mathrm{v})$, the thickness gradually increased with the amount of polymers. All the film formulations were found to have a thickness in the range of $0.023 \pm 0.04-0.05 \pm 0.01 \mathrm{~mm}$.

\section{Weight variation}

Three films each of $4 \mathrm{~cm}^{2}$ were cut at three different places from the casted film, and weight variation was determined. Weight variation varies from $29.66 \pm 1.52$ to $33 \pm 2.04 \mathrm{mg}$.

Table 4: Experimental and predicted response of optimized batch F3

\begin{tabular}{llll}
\hline S. No. & Parameters & $\begin{array}{l}\text { Predicted } \\
\text { result }\end{array}$ & $\begin{array}{l}\text { Experimental } \\
\text { result }\end{array}$ \\
\hline 1. & Disintegration time (s) & 17 & 13.33 \\
2. & In vitro \% drug release & $89.97 \%$ & $94.31 \%$ \\
3. & Folding endurance & 112 & 105 \\
& (Number of times) & & \\
\hline
\end{tabular}

Table 5: Stability studies of optimized formulation F3

\begin{tabular}{|c|c|c|c|}
\hline Parameter & Initial & After 1 month & After 2 months \\
\hline Description & $\begin{array}{l}\text { Transparent } \\
\text { and smooth }\end{array}$ & $\begin{array}{l}\text { Transparent } \\
\text { and smooth }\end{array}$ & $\begin{array}{l}\text { Transparent } \\
\text { and smooth }\end{array}$ \\
\hline DT (s) & $13.33 \pm 1.52$ & $14.19 \pm 0.18$ & $16.13 \pm 0.26$ \\
\hline $\begin{array}{l}\text { Weight of } \\
\text { film (mg) }\end{array}$ & $40.66 \pm 1.52$ & $41.25 \pm 1.33$ & $45.36 \pm 1.78$ \\
\hline $\begin{array}{l}\text { In vitro drug } \\
\text { release (\%) }\end{array}$ & $94.31 \pm 0.91$ & $92.67 \pm 0.23$ & $89.54 \pm 0.63$ \\
\hline
\end{tabular}

Data represent mean \pm standard deviation, $n=3$. DT: Disintegration time

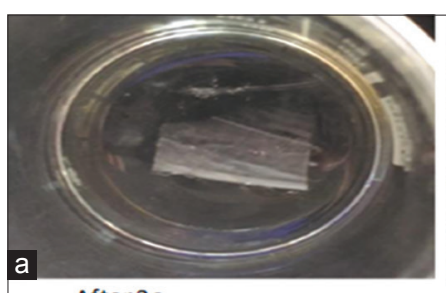

After $2 \mathrm{~s}$

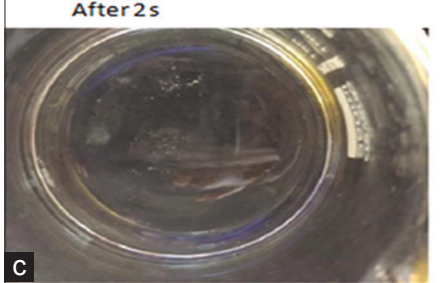

After $10 \mathrm{~s}$
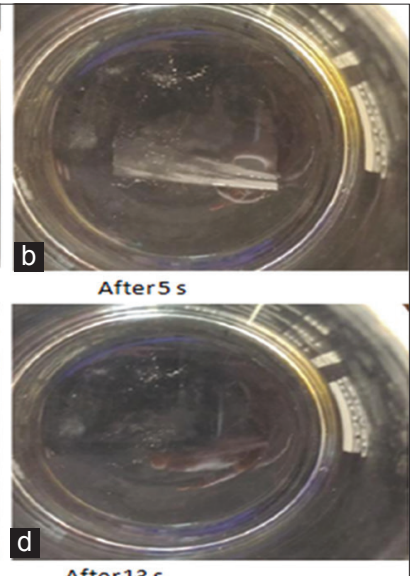

After13 s
Fig. 3: Disintegration of optimized batch at different time point. (a) After $2 \mathrm{~s}$, (b) After $5 \mathrm{~s}$, (c) After $10 \mathrm{~s}$, (d) After $13 \mathrm{~s}$
Folding endurance

It helps in determining the mechanical strength of films. Higher the value of folding endurance, higher is the mechanical strength of film. All the medicated films had satisfactory folding endurance $>90$ indicating that they were strong and flexible enough during handling and application. The highest folding endurance was found to be $105.32 \pm 1.06$ for F3. It was noticed that, as the concentration of PEG 600 increased, folding endurance of Pullulan film also increased indicating that it affects overall flexibility of film. A direct relation exists between mechanical strength and folding endurance of films. As mechanical strength is governed by plasticizer concentration, so it is clearly evident that plasticizer concentration also indirectly affects folding endurance value.

\section{Surface $\mathbf{p H}$}

Since $\mathrm{pH}$ of the saliva range from 5.5 to 7 , an attempt was made to keep the surface $\mathrm{pH}$ of the film within range. The surface $\mathrm{pH}$ of all the films varied between $6.2 \pm 0.14$ and $6.73 \pm 0.13$, the overall results were near or above 6.5 , and hence, this film may not cause any irritation in the oral cavity.

Drug content and \% moisture content

The drug content of the film was between $92 \pm 0.48$ and $86 \pm 0.53 \% \mathrm{w} / \mathrm{w}$, indicating an almost uniform drug loading in all medicated batches. A minimum of $10.11 \pm 0.33 \%$ moisture content was seen in F3 batch

\section{DT}

All film formulation denotes excellent DT almost $<25 \mathrm{~s}$ which was attributed to the presence of water-soluble excipients in the film. Amount of saliva in oral cavity is one of the important parameters for rapid disintegration in addition to low thickness of the film. The DT at different time point is shown in Fig. 3.

\section{In vitro drug release study}

Being highly water-soluble polymer, it provides rapid disintegration and dissolution of the film. This characteristic helps in the rapid onset of action of the formulation, as the drug quickly diffuses from the oral

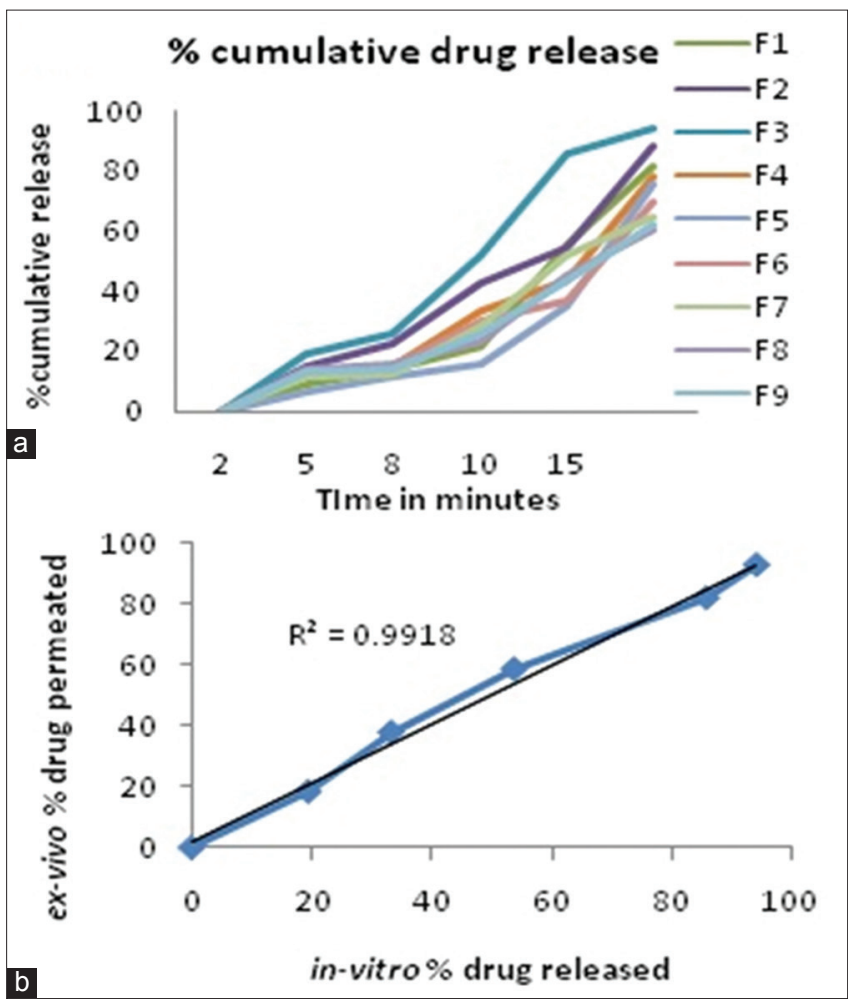

Fig. 4: (a) \% In vitro release profile of all the batches and

(b) correlation between in vitro release and ex vivo permeation of optimized batch 
mucosa and reaches the systemic circulation. The in vitro drug release profiles of the formulations in $\mathrm{pH} 6.8$ phosphate buffer show differences depending on their composition, as given in Table 1. Being the fast disintegrating formulations, the release rates of all the formulations were nearly rapid. Approximately $>60 \%$ release was observed from all the batches as illustrated in Fig. 4a and highest dissolution of $94.31 \%$ was seen in F3 formulation within 15 min. The drug release is governed by polymer content, higher amount of Pullulan resulted in release of drug at slower rate, and it may be due to reduction in the permeability due to change in the morphology of the polymer. Increased polymer concentration may have provided the matrix with lower tortuosity and poor water porosity for diffusion of drug. Moreover, higher polymer concentration would have resulted in viscous environment of the system inhibiting movement of water into the matrix for easy diffusion of the drug [15]

\section{Ex vivo permeation}

Ex vivo permeation study on optimized formulation $\mathrm{F} 3$ revealed that $92.67 \pm 0.36 \%$ of the drug was permeated within $15 \mathrm{~min}$, as shown in Fig. 4b. Good correlation was observed between in vitro drug release

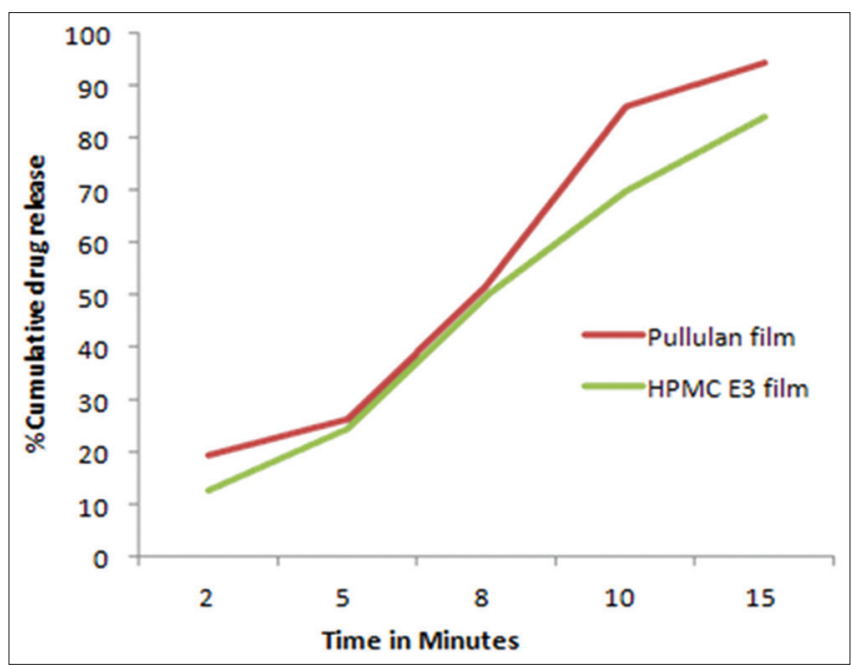

Fig. 5: In vitro \% cumulative drug release of Pullulan and hydroxypropyl methylcellulose E3 films and ex vivo permeation. This study revealed that drug directly reaches systemic circulation through the oral mucosa bypassing the first-pass metabolism [15].

Comparative results of in vitro drug release of films made up of Pullulan and HPMC E3

HPMC is known to be a polymer showing good film-forming properties. Hence, considering HPMC as a standard polymer, in vitro \% drug release between Pullulan based film was further compared with a film made up of HPMC E3, as shown in Fig. 5. The \% cumulative drug release from Pullulan film was better than the HPMC E3 film.

\section{Optimization of FDF by factorial design}

The response surface plots were generated using design expert software (Version 11, Stat-Ease Inc., USA), as shown in Fig. 4, so as to observe the effects of independent variables on the response studied such as DT, in vitro \% drug release and folding endurance, respectively. The response surface plots showed that various combinations of independent variables $X_{1}$ and $X_{2}$ may satisfy any specific requirement (i.e., DT, in vitro \% drug release and folding endurance) while taking into consideration the various factors involved in the dosage form.

Using the polynomial equations, the optimized formulation was obtained for the response parameters. In the trial runs, the optimized formulation was arrived using numerical optimization of FDF using design expert software (Version 11, Stat-Ease Inc., USA). After developing the polynomial equations for the responses Y1-Y3 with the independent variables $\mathrm{X}_{1}$ and $\mathrm{X}_{2}$, the formulation was optimized. Optimization was performed to find out the level of independent variables $\left(\mathrm{X}_{1}\right.$ and $\left.\mathrm{X}_{2}\right)$ that would yield a maximum value of FDF.

The DT, in vitro \% drug release, and folding endurance were evaluated and found within the limits. The formulation F3 was considered for model validation. The values of responses predicted from the obtained model by software and the results obtained by experimentation are shown in Table 4. The close resemblance between observed and predicted response values indicates the validity of the generated model.

The DT was increased with increase in the concentration of Pullulan and a slight change in DT was seen when concentration of PEG 600 increased while keeping Pullulan constant, as shown in Fig. 6a. Increase in Pullulan concentration resulted in decrease in \% in vitro drug release. Concentration of PEG 600 did not significantly affect the \% in

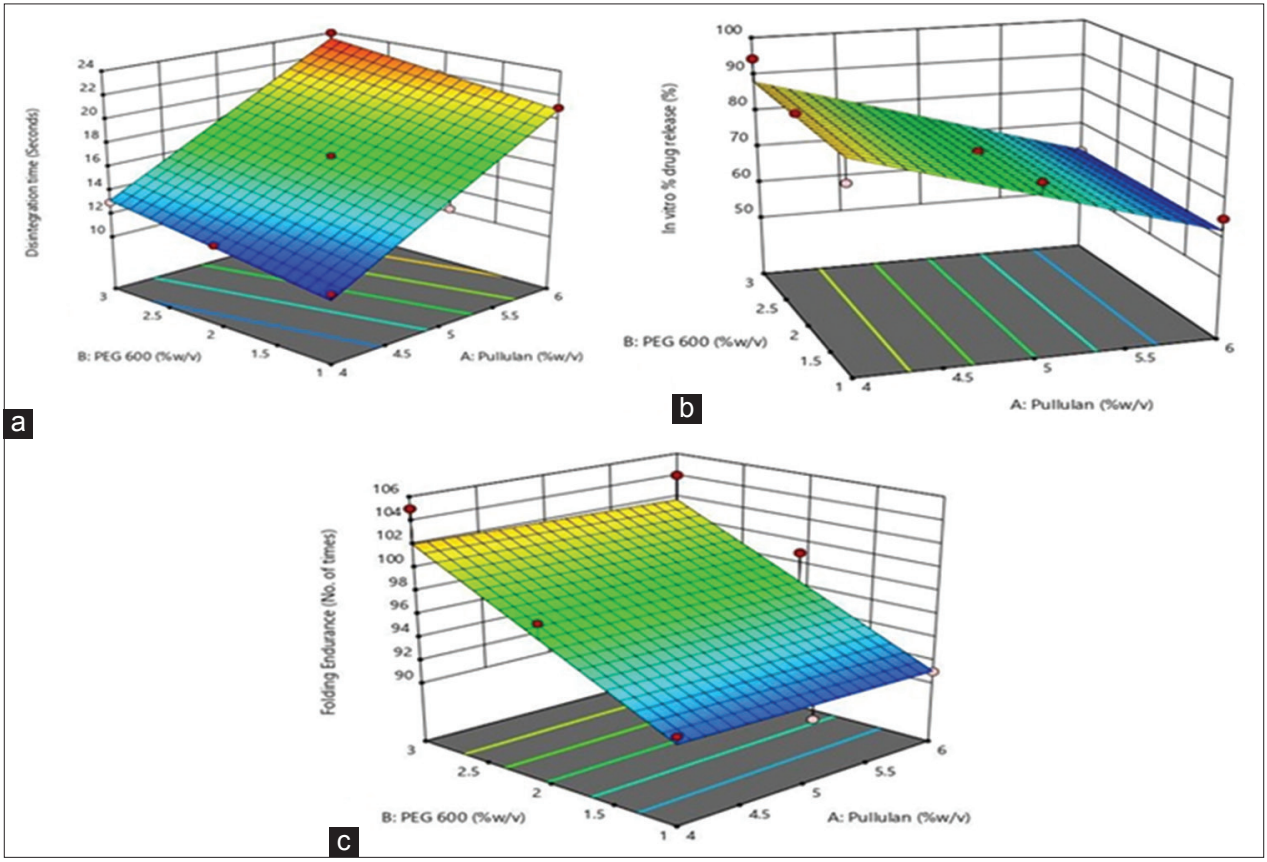

Fig. 6: Response surface plots for (a) folding endurance, (b) disintegration time and (c) In vitro \% drug release 


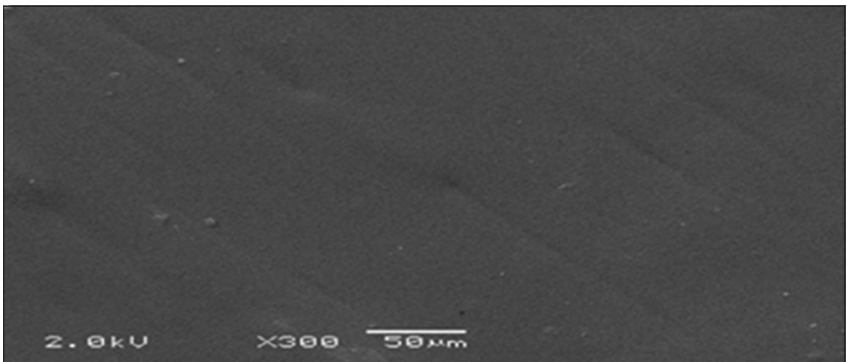

Fig. 7: Scanning electron microscope image of optimized film formulation

vitro drug release. Maximum \% in vitro drug release was observed for lower concentration of Pullulan as shown in Fig. 6b. When we increased the concentration of PEG 600 from 1\% to 3\%, there was increase in the folding endurance from 92 to 105 . PEG 600 majorly affected folding endurance than Pullulan, as shown in Fig. 6c.

\section{SEM evaluation}

The surface morphology was examined by SEM for optimized F3 film formulations, as shown in Fig. 7. The formulations showed very smooth surface at low magnification. This affirmed the smooth texture of film surface, which is one of the esthetic attributes of films. However, at microscopic level, there was high surface area, which helped in the rapid disintegration of the film. From Fig. 7, it was observed that the surface morphology showed smooth surfaces indicating uniform distribution of formulation ingredients. All the ingredients were also miscible which showed that nature of excipients was hydrophilic that resulted in complete mixing between them [16-18].

\section{Stability study}

The optimized formulation F3 was evaluated for stability studies which were stored at $40^{\circ} \mathrm{C} \pm 2^{\circ} \mathrm{C} / 75 \% \pm 5 \%$ RH for 2 months and were analyzed for physical appearance, DT, weight of film, and in vitro \% drug release rate after particular time interval. The results are shown in Table 5. The physical appearance of the film was good, smooth, and transparent till the end of duration. It was found that films retained its physical appearance and there was not much significant change in the values. No statistically significant changes were observed in DT of the film, weight of film and in vitro drug release (\%) after 2 months [19].

\section{CONCLUSION}

FDF of PXH using Pullulan as a natural biodegradable film former, PEG 600 as a plasticizer was successfully formulated at lab-scale by solvent casting method. Based on the results, it was found that Pullulan showed potential negative effect on the drug release rate while Plasticizer PEG 600 directly affected mechanical strength of film thus in turn affecting folding endurance. The use of film forming polymers in dissolvable films has attracted considerable attention in medical and nutraceutical applications. The water-soluble polymers achieve rapid disintegration, good mouth feel and mechanical properties to the films. Pullulan is a natural polymer obtained from non animal origin and does not require chemical modification. Thus, it can be concluded that FDF formulation using Pullulan as natural polymer can be an innovative and promising approach for the delivery of PXH.

\section{ACKNOWLEDGMENT}

The authors are thankful to Sun Pharmaceutical Industries Ltd., Mumbai, and Gangawal chemicals, Mumbai, for providing PXH and Pullulan as gift sample.

\section{AUTHORS' CONTRIBUTIONS}

Farheen Ali: The main researcher, design of problem, experimental study. Rita Wadetwar: Corresponding author, designing of problem, manuscript preparation, and manuscript correction. Pranita Kanojiya: Manuscript preparation and manuscript correction.

\section{CONFLICTS OF INTEREST}

The authors declare that there are no conflicts of interest. The contents of the paper have not been submitted for publication in any of the journals.

\section{REFERENCES}

1. Pimparade MB, Vo A, Maurya AS, Bae J, Morott JT, Feng X, et al. Development and evaluation of an oral fast disintegrating anti-allergic film using hot-melt extrusion technology. Eur J Pharm Biopharm 2017;119:81-90.

2. Prajapati VD, Chaudhari AM, Gandhi AK, Maheriya P. Pullulan based oral thin film formulation of zolmitriptan: Development and optimization using factorial design. Int J Biol Macromol 2018;107:2075-85.

3. Patel P, Patel J, Patel K, Shah N, Shah S. A review on fast dissolving sublingual film. J Pharm Sci Bio Sci Res 2015;5:279-85.

4. Belzung C, Willner P, Philippot P. Depression: From psychopathology to pathophysiology. Curr Opin Neurobiol 2015;30:24-30.

5. Prajapati PH, Oza M, Shah HM, Patel CB. Formulation and evaluation of sublingual tablet of paroxetine hydrochloride. Int J Pharm Res Bio Sci 2014;3:1019-36.

6. Wadetwar RN, Charde T. Design, development, and characterization of oromucosal wafer of tramadol hydrochloride. Asian J Pharm Clin Res 2018;11:116-22.

7. Patil P, Shrivastava SK. Formulation, evaluation and optimization of fast dissolving oral film of selective antihypertensive drug. World J Pharm Pharm Sci 2014;3:996-1060.

8. Koland M, Sandeep V, Charyulu N. Fast dissolving sublingual films of ondansetron hydrochloride: Effect of additives on in vitro drug release and mucosal permeation. J Young Pharm 2010;2:216-22.

9. Sumitha CH, Varma MV, Sriniwas K. Development of taste masked fast dissolving orally consumable films of seldinafil citrate. IJPIS J Pharm Cosmet 2011;1:1-6.

10. Navamanisubramanian $R$, Nerella R, Chamundeeswari D, Shanmuganathan S. Use of okra mucilage and chitosan acetate in verapamil hydrochloride buccal patches development; in vitro and ex vivo characterization. J Young Pharm 2017;9:94-9.

11. Nalluri BN, Sravan IB, Saisri AV, Sribramhini R, Maheswari KM. Development and evaluation of mouth dissolving films of sumatriptan succinate for better therapeutic efficacy. J Appl Pharm Sci 2013;3:161-6.

12. Singh S. Drug stability testing and shelf-life determination according to international guidelines. Pharm Tech 1999;23:68-88.

13. Kunte S, Tandale P. Fast dissolving strips: A novel approach for the delivery of verapamil. J Pharm Bioallied Sci 2010;2:325-8.

14. Patel VM, Prajapati BG, Patel MM. Design and characterization of chitosan-containing mucoadhesive buccal patches of propranolol hydrochloride. Acta Pharm 2007;57:61-72.

15. Bhupinder B, Jangra S. Formulation and evaluation of fast dissolving sublingual films of rizatriptan benzoate. Int J Drug Dev Res 2012;4:133-43.

16. Daud A, Peepliwal A, Bonde M, Sapkal N, Gaikwad N. Design and development of Nicotiana tabacum film using factorial design. Int $\mathrm{J}$ Pharm Pharm Sci 2016;8:115-23.

17. Ghada EY, Haidy AB. Design and evaluation of fast dissolving oro-dispersible films of metoclopramide hydrochloride using $3^{2}$ multifactorial designs. Int J Pharm Pharm Sci 2016;8:218-22.

18. Kaur G, Singh D, Brar V. Bioadhesive okra polymer based buccal patches as platform for controlled drug delivery. Int J Biol Macromol 2014;70:408-19.

19. Khanna R, Agarwal SP, Ahuja A. Preparation and evaluation of mucoadhesive buccal films of clotrimazole for oral Candida infections. Indian J Pharm Sci 1997;59:299-305. 